
\title{
25 Research Square \\ Sex Differences in Rumen Fermentation and Microbiota of Tibetan Goat
}

\section{Xinyu Guo}

Gansu Agricultural University https://orcid.org/0000-0002-4329-6230

\section{Yuzhu Sha}

Gansu Agricultural University

\section{Weibing Lv}

Gansu Agricultural University

\section{Xiaoning Pu}

Gansu Agricultural University

Xiu Liu ( $\sim$ liuxiu@gsau.edu.cn )

liuxiu@gsau.edu.cn https://orcid.org/0000-0001-6057-2551

\section{Yuzhu Luo}

Gansu Agricultural University

Jiang $\mathrm{Hu}$

Gansu Agricultural University

\section{Jiqing Wang}

Gansu Agricultural University

\section{Shaobin Li}

Gansu Agricultural University

\section{Zhidong Zhao}

Gansu Agricultural University

\section{Research}

Keywords: Tibetan goat, Rumen microbiota, Sex differences, VFAs, Gene expression

Posted Date: November 17th, 2021

DOI: https://doi.org/10.21203/rs.3.rs-1070699/v1

License: (9) This work is licensed under a Creative Commons Attribution 4.0 International License. Read Full License 
Version of Record: A version of this preprint was published at Microbial Cell Factories on April 7th, 2022. See the published version at https://doi.org/10.1186/s12934-022-01783-8. 


\section{Abstract}

Background: Gut microbiota play an important role in maintaining host metabolism, immune system and health, while sex, genotype, diet and health have certain effects on composition of gut microbiota. Therefore, in order to explore the sex differences in the structure and function of rumen microbiota in Tibetan goat, the study analyzed the sex differences in rumen fermentation parameters, rumen microbiota and the expression of genes related to VFAs transport in Tibetan goat.

Results: The results showed that the content of acetic acid in the rumen of rams was significantly higher than that of ewes $(P<0.05)$, and propionic acid and butyric acid were higher than that of ewes, but the difference was not significant ( $P>0.05)$; The expression of VFAs transport related genes DRA, AE2, MCT-1, $N H E 1, N H E 2$ in rumen epithelium of ewes was significantly higher than that of rams. Analysis of the composition and structure of rumen microbiota showed that there were significant sex differences in structure of rumen microbiota, and the abundance of rumen microbiota in ewes was higher than that in rams $(P>0.05)$. At the phylum level, Firmicutes and Bacteroidetes were the dominant phyla of Tibetan goat, while Firmicutes was significantly higher in ewes than in rams $(P<0.05)$. At the genus level, the relative abundance of Fibrobacter, Ruminococcus_ 1 and Pyramidobacter in ewes was significantly higher than that in rams $(P<0.05)$. The function prediction results showed that Replication, recombination and repair, RNA processing and modification were mainly enriched in ewes $(P<0.05)$.

Conclusions: Correlation analysis revealed significant associations of some rumen microbiota with the fermentation product VFAs and VFAs transport-related genes. It is concluded that rams and ewes have a strong ability for fermenting and metabolizing when adapting to the plateau environment, which provides a certain sex reference basis for Tibetan goat adaptation to the plateau environment.

\section{Introduction}

Tibetan goat is an important genetic resource of livestock on the Qinghai-Tibet Plateau, which is famous for producing high-quality cashmere and is the dominant animal breed in the development of seasonal animal husbandry in the Qinghai-Tibet Plateau [7]. Living in the alpine region with an altitude of 2500$5000 \mathrm{~m}$, they can adapt to special environmental pressures such as low oxygen, low temperature, low pressure and strong ultraviolet radiation in the plateau [1]. Through long-term natural selection, Tibetan goat have acquired stable genetic characteristics in physiology, biochemistry and morphology, indicating the unique adaptability of plateau species during the long time evolution $[8,9]$. Gut microbes play an important role in the adaptive process of plateau animals. Studies have found that rumen microbiota of Tibetan sheep underwent significant changes when they adapted to the cold season, and host genome was significantly correlated with rumen microbiota and metabolites [11]. The metagenomic sequencing of plateau ruminant Yak and Tibetan sheep showed that rumen microbiota related genes were significantly enriched in the pathway of VFAs production, and the energy pathway enriched by VFAs was essential for the adaptive evolution of plateau animals [4]. Studies have reported that there was a significant correlation between rumen fermentation parameters and microbiota composition of yak, and 
the composition and function of microbiota can be comprehensively understood through correlation analysis of metabolites [10]. The interaction of rumen microbiota and metabolites had an important impact on the health of the host. Under cold stress conditions, sheep improve the self-protection mechanism by regulating the relative abundance of rumen microbiota and the concentration of related metabolites [17]. Studies have found that heat stress changed the composition of the microbial community and significantly affected the host energy metabolism on the composition of rumen microbiota of goat under different temperature and humidity conditions [12].

The composition of animal gut microbiota is affected by a variety of factors, including diet, breed, age, antibiotics, stress, psychology, maternal health, delivery mode, environment and exercise, etc., which all affect the diversity of gut microbiota [2]. Studies have found that the microbiota caused by sex differences has great differences in hormone secretion, energy metabolism, immune response and intestinal parameters [3]. Sex differences play a crucial role in shaping the gut microbiota. Sinha et al. pointed out that the composition of gut microbiota is significantly different between men and women, and women have higher microbiota diversity than men [13]. The same result was also found in the study of mouse that the diversity and richness of gut microbiota in female mouse was higher than that in male mouse [25]. Sex differences in gut microbiota play a key role in the growth and metabolism of the host. For example, Markle et al. found that fecal transplantation from male mouse to female mouse significantly changed the microbiome and metabolome of subjects, which increased testosterone level, relieved islet inflammation, and protected T1D development of non-obese diabetic mouse [5]. The microbiota can affect innate and adaptive immunity, which indirectly reflected the level of disease resistance caused by sex differences [6]. Therefore, we conducted a comparative analysis of the rumen fermentation function, host-related gene expression and microbiota structure in Tibetan goat of different sex to understand the changes in the rumen environment and host gene expression in Tibetan goat of different sex, in order to put forward new ideas into the interaction between rumen microbiota-VFAs-host genes, which provided a basis for the study of growth and development and feeding patterns in Tibetan goat of different sex, and also provided a reference for the protection and utilization of Tibetan goat germplasm resources.

\section{Materials And Methods}

\section{Experimental animals}

The samples were collected from goats in Maqu County, Gansu Province in July 2019, at an altitude of about 3,700 m. Eight healthy Tibetan goats (Each half of ewes and rams) with similar age (1 year \pm 1 month old) were selected in the local traditional natural grazing management state and grazed naturally in the same pasture without any supplementary feeding.

\section{Collection of animal samples}

Before grazing in the morning, rumen fluid of Tibetan goat was collected with a gastric tube rumen sampler, and $50 \mathrm{~mL}$ of rumen fluid was collected from each goat. The samples were divided into 
cryopreservation tubes and quickly placed into liquid nitrogen tanks and brought back to the laboratory for storage at $-80^{\circ} \mathrm{C}$. The samples were used for the determination of $16 \mathrm{~S}$ rRNA, volatile fatty acid (VFAs) content and ammonia nitrogen $\left(\mathrm{NH}_{3}-\mathrm{N}\right)$ content. After slaughter by neck blood leting, the rumen was taken out immediately, a small piece of rumen ventral sac tissue was cut out, and the contents of the tissue were washed off quickly with normal saline. After that, the rumen epithelial tissue was separated with blunt scissors, and stored in liquid nitrogen in cryopreservation tube, which was brought back to the laboratory for storage at $-80^{\circ} \mathrm{C}$ for RNA extraction.

\section{Collection of forage sample}

In the grazing field of experimental animals, the sample squares $(1 \mathrm{~m} \times 1 \mathrm{~m})$ were used to collect forage samples, and 5 squares $(1 \mathrm{~m} \times 1 \mathrm{~m})$ were randomly placed with a distance of more than $10 \mathrm{~m}$. The ground part of forage samples were collected and the samples was cut out with scissors. The sample of each square was dried in a laboratory oven at $60^{\circ} \mathrm{C}$ for 24 hours to constant weight, then ground in a mill and passed through a $1 \mathrm{~mm}$ sieve for further analysis. The Van Soest method was used to determine the concentration of acid detergent fiber (ADF) and neutral detergent fiber (NDF) in 5 samples [30]. The AOAC method was used to determine dry matter (DM), crude protein (CP), crude fatty ether extract (EE), crude Ash (Ash), calcium and phosphorus [24]. The measurement results are shown in Table 4.

Table 4 Summary nutrient determination results of plateau forage $\% \rrbracket$

\begin{tabular}{cccccccc}
\hline CP & EE & DM & Ash & NDF & ADF & Ca & P \\
\hline 10.64 & 4.07 & 5.39 & 6.95 & 54.95 & 32.15 & 0.84 & 1.14 \\
\hline
\end{tabular}

\section{Determination of rumen fermentation parameters}

VFAs were determined by Shimadu (GC-2010 PLUS) gas chromatograph with internal standard method and internal standard is 2-ethylbutyric acid (2EB). The chromatographic column was an AT-FFAP (50 $\mathrm{m} \times$ $0.32 \mathrm{~mm} \times 0.25 \mathrm{~m}$ ) capillary column. The determination was performed on an AT-FFAP capillary column $(50 \mathrm{~m} \times 0.32 \mathrm{~mm} \times 0.25 \mu \mathrm{m})$. The column temperature was maintained at $60^{\circ} \mathrm{C}$ for $1 \mathrm{~min}$, then increased to $115^{\circ} \mathrm{C}$ at $5^{\circ} \mathrm{C} / \mathrm{min}$ without reservation, and then increased to $180^{\circ} \mathrm{C}$ at $15^{\circ} \mathrm{C} / \mathrm{min}$. The detector temperature was $260^{\circ} \mathrm{C}$ and the injector temperature was $250^{\circ} \mathrm{C}$. The content of $\mathrm{NH}$ - $\mathrm{N}$ in rumen fluid was determined by spectrophotometer colorimetry. Cellulase $(\mathrm{CL})$ activity assay kit (Suzhou Keming Biotechnology Company Limited, China) was used to determine the activity of cellulase in rumen fluid.

\section{DNA extraction, high-throughput sequencing and colony density determination}

The bacterial DNA was isolated from each rumen sample using MN NucleoSpin 96 Soil kit (MachereyNagel, Germany). The bacterial V3-V4 region of 16S rRNA genes in the total DNA were amplified using the primers (forward primer 338F: 5'- ACTCCTACGGGAGgCAGCA-3' and reverse primer 806R: 5'- 
GGACTACHVGGGTWTCTAAT-3' ). Rumen microbiota was sequenced using two-step library construction method, and amplified products were sequenced on Illumina MiSeq 2500 (Illumina, San Diego, CA, USA) platform [19]. Using rumen microbiora DNA as a template, methanogens, protein-degrading bacteria and fibre-degrading bacteria were selected for population density determination and analysis (see Table 5 for sequence information). Bacteria were taken as internal reference, and bacterial primers referred to the study of Muyze et al. [14].

Table 5 Primer sequences of microbiota

\begin{tabular}{|c|c|c|c|c|}
\hline Gene & $\operatorname{Primer}\left(5^{\prime}-3^{\prime}\right)$ & Length & $\begin{array}{l}\text { Annealing } \\
\text { temperature }\end{array}$ & $\begin{array}{l}\text { Accession } \\
\text { number }\end{array}$ \\
\hline bacterium & $\begin{array}{l}\text { F:CCTACGGGAGGCAGCAG } \\
\text { R:TTACCGCGGCTGCTGG }\end{array}$ & $181 \mathrm{bp}$ & $60^{\circ} \mathrm{C}$ & * \\
\hline $\mathrm{Rf}$ & $\begin{array}{l}\text { F:TATCTTAGTGGCGGACGGGT } \\
\text { R:TCTAATCAGACGCGAGCCCA }\end{array}$ & $157 \mathrm{bp}$ & $60^{\circ} \mathrm{C}$ & MT356193.1 \\
\hline Fs & $\begin{array}{l}\text { F:GATGAGCTTGCGTCCGATT } \\
\text { R:ATTCCCTACTGCTGCCTCC }\end{array}$ & $110 \mathrm{bp}$ & $60^{\circ} \mathrm{C}$ & EU606019.1 \\
\hline $\mathrm{Ra}$ & $\begin{array}{l}\text { F:GGGCTTAACCCCTGAACTGC } \\
\text { R:TCGCCACTGATGTTCCTCCT }\end{array}$ & $114 \mathrm{bp}$ & $60^{\circ} \mathrm{C}$ & X85098.1 \\
\hline Ram & $\begin{array}{l}\text { F:GGGGACAACACCTGGAAACG } \\
\text { R:CTTGGTAGGCCGTTACCCCA }\end{array}$ & $124 \mathrm{bp}$ & $60^{\circ} \mathrm{C}$ & Y15992.1 \\
\hline $\mathrm{Bf}$ & $\begin{array}{l}\text { F:CCTGACTAAGAAGCACCGGC } \\
\text { R:GTAAAACCGCCTACGCTCCC }\end{array}$ & $107 \mathrm{bp}$ & $60^{\circ} \mathrm{C}$ & U41167.1 \\
\hline MB & $\begin{array}{l}\text { F:TCTGTACGGGTTGTGAGAGCA } \\
\text { R:CGCGATTTCTCACATTGCGG }\end{array}$ & $106 \mathrm{bp}$ & $60^{\circ} \mathrm{C}$ & KP752401.1 \\
\hline
\end{tabular}

Determination of mRNA expression in rumen epithelial tissue 
Total RNA was extracted from rumen epithelial tissues of Tibetan goat using the Trizol reagent method (TransGen). The concentration and purity of RNA were determined by ultramicro spectrophotometer (Therm Nano drop-2000). Using a reverse transcription kit (HiScript ${ }^{\circledR}$ II Q RT SuperMix for qPCR; Nanjing, China) to synthesize cDNA. Specific primers were designed using Primer 5.0 software (Table 6). An Applied Biosystems Q6 Quantitative PCR instrument was used to quantify fluorescence of the rumen epithelium-related genes and the internal reference gene. The resulting data were analyzed using the $2^{-}$ $\Delta \Delta \mathrm{CT}$ method and $\beta$-actin as the internal reference gene for correction. Reaction conditions: $95^{\circ} \mathrm{C}$ predenaturation for $30 \mathrm{~s}$; Cyclic reaction at $95^{\circ} \mathrm{C}$ for $10 \mathrm{~s}, 60^{\circ} \mathrm{C}$ for $30 \mathrm{~s}, 40$ cycles; Dissolution curve $\left(95^{\circ} \mathrm{C}\right.$ for $15 \mathrm{~s}, 60^{\circ} \mathrm{C}$ for $60 \mathrm{~s}, 95^{\circ} \mathrm{C}$ for $\left.15 \mathrm{~s}\right)$.

Table 6 Primer sequences of fatty acid-related genes

\begin{tabular}{|c|c|c|c|c|}
\hline Gene & Primerl5'-3'] & Length & $\begin{array}{l}\text { Annealing } \\
\text { temperature }\end{array}$ & $\begin{array}{l}\text { Accession } \\
\text { number }\end{array}$ \\
\hline \multirow{2}{*}{$\begin{array}{l}\beta- \\
\text { actin }\end{array}$} & F:AGCCTTCCTTCCTGGGCATGGA & \multirow[t]{2}{*}{ 113bp } & \multirow[t]{2}{*}{$60^{\circ} \mathrm{C}$} & \multirow[t]{2}{*}{ NM_001009784.3 } \\
\hline & R:GGACAGCACCGTGTTGGCGTAGA & & & \\
\hline \multirow[t]{2}{*}{$D R A$} & F:TGTGGCGGCTTCCAGAATTT & \multirow[t]{2}{*}{ 167bp } & \multirow[t]{2}{*}{$60^{\circ} \mathrm{C}$} & \multirow[t]{2}{*}{ NM_001280717.1 } \\
\hline & R:CACAGGCTTGTTTGGGAGCA & & & \\
\hline \multirow[t]{2}{*}{ MCT1 } & F:GGACTGTGTCATCTGGCAGC & \multirow[t]{2}{*}{ 134bp } & \multirow[t]{2}{*}{$60^{\circ} \mathrm{C}$} & \multirow[t]{2}{*}{ XM_004002335.4 } \\
\hline & R:TGGGGTCCAACAAGGTCCAT & & & \\
\hline \multirow[t]{2}{*}{$A E 2$} & F:AAGATCCCTGAGAACGCCGA & \multirow[t]{2}{*}{ 152bp } & \multirow[t]{2}{*}{$60^{\circ} \mathrm{C}$} & \multirow[t]{2}{*}{ XM_027969012.1 } \\
\hline & R:AGCAGAAAGAGGAAGCGCAC & & & \\
\hline \multirow[t]{2}{*}{ NHE2 } & F:TTCTTTGTCGTGGGGATCGG & \multirow[t]{2}{*}{ 180bp } & \multirow[t]{2}{*}{$60^{\circ} \mathrm{C}$} & \multirow[t]{2}{*}{ XM_027967037.1 } \\
\hline & R:CGTGATTGCCATGATGCCTG & & & \\
\hline \multirow[t]{2}{*}{ MCT4 } & F:ACGGCTCAGCCTTAGTAAACTTC & \multirow[t]{2}{*}{ 144bp } & \multirow[t]{2}{*}{$60^{\circ} \mathrm{C}$} & \multirow[t]{2}{*}{ NC_0402252.1 } \\
\hline & R:AATGGAGTTGTGCGAGTTGGT & & & \\
\hline \multirow[t]{2}{*}{ NHE1 } & F:GCTTCTTCGTGGTGTCCCTG & \multirow[t]{2}{*}{ 174bp } & \multirow[t]{2}{*}{$60^{\circ} \mathrm{C}$} & \multirow[t]{2}{*}{ XM_004005085.4 } \\
\hline & R:CCATGATGCCTGACAGGTGG & & & \\
\hline
\end{tabular}

\section{Bioinformatics analysis}

Quality assessment of the original sequencing data: the original sequencing reads are denoised, pairedend spliced (FLASH, version 1.2.11), quality filtered (Trimmomatic, version0.33), and chimera removed (UCHIME, version 8.1). The Usearch software (Version 10.0) was used to cluster the high quality effective Tags with the 2013 Greengenes (version 13.8) ribosome database at $97 \%$ similarity level. Operational taxonomic units (OTUs) was filtered with $0.005 \%$ of all sequences sequenced as the threshold, and 
species annotation and taxonomic analysis were performed on OTU based on Silva (Bacteria 16S) database [15].

Alpha diversity analysis was performed on OTU analysis results by Mothur (version V.1.30), and the Rarefaction Curve and Shannon Index Dilution Curve were plotted. Different species between groups were obtained by LefSe analysis.

Finally, PICRUST software was used to compare the species composition information obtained from $16 \mathrm{~S}$ sequencing data to analyze the functional differences among different groups. KEGG (Kyoto Encyclopedia of Genes and Genomes) difference analysis was performed to observe the differences and variations in metabolic pathways of functional genes in microbial communities among different groups of samples. COG (Clusters of Orthologous Groups of proteins) analysis predicts the differences and changes of prokaryotic functions between different groups.

\section{Statistical data analysis}

The independent sample T test in SPSS software (version 24.0, SPSS Inc.) was used to analyze differences in rumen fermentation parameters (VFAs), CL activity and Alpha diversity index (Ace index, Chao1 index, Shannon index and Simpson index) of Tibetan goat of different sex. Linear discriminant analysis (LDA) effect size (LEfSe) method was used to evaluate the differences of microbial communities, and the LDA score threshold was 4 . The analysis data were all expressed as Mean \pm SD, and the statistical significance level is $P<0.05$. Spearman was used for correlation test.

\section{Results}

\section{Determination results of VFAs, $\mathrm{NH}_{3}-\mathrm{N}$ and $\mathrm{CL}$}

There were certain differences for VFAs in the rumen fluid of Tibetan goat of different sex (Table 1). The total VFAs content of rams were extremely higher than that of ewes $(P<0.01)$. Acetic acid was significantly difference between different sexes, which was manifested as that rams were significantly higher than ewes $(P<0.05)$. The concentration of propionic acid, isobutyric acid, butyric acid, isovaleric acid and valeric acid in ewes was higher than that in ewes, but there was no significant difference $(P>0.05)$. The NH3-N content in rams was higher than that of ewes ( $P>0.05)$. The fluid cellulase (CL) activity showed that rams were higher than ewes ( $P>0.05)$.

Table 1 Rumen fermentation parameters of Tibetan goat of different sex 
Table 1 Rumen fermentation parameters of Tibetan goat of different sex

\begin{tabular}{lccc}
\hline \multicolumn{1}{c}{ Item } & \multicolumn{1}{c}{ TGM } & TGFM & \multicolumn{1}{c}{$\boldsymbol{P}$} \\
\hline Concentration $(\mathrm{mmol} / \mathrm{L})$ & & & $<0.01$ \\
Acetic acid & $38.05 \pm 1.30$ & $22.97 \pm 0.23$ & 0.02 \\
propionic acid & $10.39 \pm 1.03$ & $6.85 \pm 1.97$ & 0.19 \\
Isobutyric acid & $1.05 \pm 0.13$ & $0.92 \pm 0.12$ & 0.32 \\
Butyrate acid & $5.26 \pm 0.87$ & $4.50 \pm 1.08$ & 0.82 \\
Isovaleric acid & $1.07 \pm 0.07$ & $0.94 \pm 0.11$ & 0.09 \\
Valeric acid & $1.29 \pm 0.50$ & $1.22 \pm 0.19$ & 0.81 \\
A/P & $4.17 \pm 1.90$ & $3.56 \pm 0.97$ & $<0.01$ \\
Total VFAs & $52.03 \pm 5.08$ & $36.96 \pm 2.25$ & 0.78 \\
NH3-N $(\mathrm{mg} / 100 \mathrm{ml})$ & $39.97 \pm 6.40$ & $40.96 \pm 2.31$ & 0.14 \\
CL $(\mu \mathrm{g} / \mathrm{min} / \mathrm{ml})$ & 157.19 & 154.56 & \\
\hline
\end{tabular}

NOTE:TGM indicates rams,TGFM indicates ewes;A/P indicates Acetic acid/Propionic acid.

\section{Expression determination of VFAs absorption related genes}

There were differences in expression of genes related to VFAs transport in rumen epithelium between ewes and rams (Fig. 1). The relative expression levels of $A E 2, D R A, N H E 1, N H E 2$ and MCT-1 in ewes were significantly higher than those in rams $(P<0.05)$. The expression levels of $D R A, M C T-1$ and NHE1 were extremely significant difference between ewes and rams $(P<0.01)$ and there was no significant difference in the expression of MCT-4 (P>0.05). Moreover, The expression of MCT-1 in ewes was 1544 times, 16 times, 7538 times, 56 times and 130 times of AE2, DRA, MCT-4, NHE1 and NHE2, respectively.

\section{Diversity of rumen microbiota}

A total of 612,007 pairs of reads were obtained in this study, and 610,284 clean reads were generated after tiling and filtering of double-ended reads, and at least 62,730 clean reads were generated for each sample, with an average of 76,286 clean reads were produced. Usearch software was used to cluster 
Tags at the similarity level of $97 \%$ to obtain the number of OTUs of each sample. A total of 969 OTU were obtained, including 945 OTU in rams and 945 OTU in ewes, and 12 unique OTU for each(Fig. 2A). The dilution curve described the species diversity and species richness of each sample, and the flattening of the curve at 30,000 reads indicated that the sequencing coverage was saturated (Fig. 2B). Alpha diversity analysis (Table 2) showed that the ewes were lower than the rams about ACE and Chao1 indexes, but the difference was not significant $(P>0.05)$, while the Shannon and Simpson indexes were that the ewes were higher than the rams, but the difference was also not significant $(P>0.05)$.

Table 2 Alpha diversity

\begin{tabular}{cccc}
\hline Index_type & TGFM & TGM & $p$ \\
\hline Shannon & 7.47 & 7.44 & 0.87 \\
Simpson & 0.99 & 0.98 & 0.33 \\
ACE & 848.31 & 851.82 & 0.88 \\
Chao1 & 868.23 & 891.64 & 0.38 \\
\hline
\end{tabular}

\section{The composition of rumen microbiota}

At the taxonomic level, a total of 15 phyla, 14 classes, 31 orders, 55 families, 129 genera , and 156 species were detected in this study. At the phylum level, Bacteroidetes and Firmicutes were the dominant phylum, and their relative abundances were all greater than $1 \%$ (Fig. $3 \mathrm{~A}$ ). The relative abundance of Bacteroidetes and Firmicutes was the highest in both ewes and rams, accounting for more than $70 \%$ of the total abundance. In addition, different species at the phylum level such as Firmicutes, Fibrobacteres and Spirochaetes were the dominant phyla, and the relative abundance of three different species in ewes was significantly higher than that of rams $(P<0.05)$. At the genus level (Fig. 3B), there were 56 genera with relative abundance greater than $0.1 \%$, and Prevotella_ 1 was the dominant genus in the rumen of both rams and ewes.A total of 13 different species were identified among 129 genera $(P<0.05)$. The relative abundance of Fibrobacter, Ruminococcus_1, uncultured_bacterium_f_Prevotellaceae, Erysipelotrichaceae_UCG-004, Oscillospira, Pyramidobacter and uncultured_bacterium_f_Mitochondria in ewes was significantly higher than that of rams $(P<0.05)$. In addition, the relative abundance of Lachnospira and Ruminococcaceae_NK4A214_group was significantly higher than that of ewes $(P<0.05)$. LEfSe analysis of samples between groups found (Fig. 4) that there were statistically different biomarkers between ewes and rams (LDA score>4), and there were seven differential biomarkers in rams, and differences were significant between ewes and rams.

\section{Prediction of rumen microbiota function}


A total of 46 KEGG gene families and 25 COG gene families were identified in the $16 \mathrm{~S}$ rRNA gene sequencing data using PICRUSt software to predict gene function. Among these predictions, $2 \mathrm{COG}$ gene families showed significant differences between ewes and rams. Of the $43 \mathrm{KEGG}$ gene families, the vast majority were pathways related to metabolism, of which the largest proportion was the function related to carbohydrate metabolism, followed by Amino Acid metabolism and energy metabolism. There were no significant differences that amino acid metabolism and nucleotide metabolism were higher than in ewes that in rams ( $P>0.05)$. Among the $25 \mathrm{COG}$ gene families, the functions related to Replication, recombination and repair, RNA processing and modification (Table 3 ) showed that ewes were significantly higher than rams $(P<0.05)$;

Table 3 Gene Ontology (GO) and Kyoto Encyclopedia of Genes and Genomes (KEGG) enrichment analysis

\begin{tabular}{lllll}
\hline Class1 & Class2 & TGFM & TGM & P \\
\hline
\end{tabular}

\section{Function prediction of KEGG gene family}

\begin{tabular}{lcccc} 
Metabolism & Carbohydrate metabolism & 9.40 & 9.40 & 0.97 \\
Metabolism & Amino acid metabolism & 6.75 & 6.72 & 0.45 \\
Metabolism & Energy metabolism & 4.09 & 4.23 & 0.15 \\
\hline
\end{tabular}

\section{Function prediction of COG gene family}

$\begin{array}{ccccc}\text { Information storage } & \text { Replication, recombination } & 5.75 & 5.64 & 0.03 \\ \text { and processig } & \text { and repair } & & & \end{array}$

Information storage RNA processing and

and processig modification

$0.0040 \quad 0.0016 \quad 0.02$

\section{Determination of rumen microbial community density}

Fig. 5 shows that there were significant differences in the density of the rumen microbiota of different sex in Tibetan goat. Butyrivibrio fibrisolvens had the highest relative expression in Tibetan goat of different sex, and was significantly higher than other microbiota $(P<0.05)$. In the rumen microbiota of different sex, the relative expression of Fibrobacter succinogenes, Ruminococcus albus and Metha nogenic bacteria were higher in ewes than in rams, while Ruminococcus albus and Methanogens were significantly different between rams and ewes $(P<0.05)$. The relative expression levels of Butyrivibrio fibrolytica, 
Ruminobacter amylophilus and Ruminococcus flavanum were higher in rams than ewes, and the difference was not significant ( $P>0.05)$.

\section{Interactions between rumen microbiota,VFAs and expressions of genes related to transport}

As shown in fig. 6 , the correlation heat map (correlation threshold $>0.5$ ) was constructed between rumen microbiota (top 20 genus level microorganisms with relative abundance) and VFAs and rumen epithelium mRNA expression $\left(2^{-\Delta \Delta C T}\right)$ of Tibetan goat. There was significant negative correlation between VFAs and the three genus level microorganisms $(P<0.05)$ and significant positive correlation between VFAs and other three genus level microorganisms ( $P>0.05)$. Furthermore, Ruminococcaceae_NK4A214_group and Prevotellaceae_UCG-003 showed significant positive correlated with VFAs $(P<0.05)$,

while Ruminococcaceae_NK4A214_group was positively correlated with acetic acid in a significant way $(P<0.05)$. Moreover, Treponema_2, Fibrobacter and Ruminococcus_1 showed significant correlated with VFAs $(P<0.05)$. Uncultured_bacterium_f_Lachnospiraceae, Butyrivibrio_2 and Prevotellaceae_UCG-001 were negatively correlated with ammonia nitrogen $(P<0.05)$.

In addition, the genes related to VFAs transport were correlated with eight genus level microorganisms. Ruminococcus_ 1 was significantly positively correlated with NHE2 and MCT-1 $(P<0.05)$, and negatively correlated with acetic acid $(P<0.05)$. Fibrobacter showed significant positive correlation with $\mathrm{NHEI}(P<0.05)$, and significant negative correlation with acetic acid $(P<0.05)$. Prevotellaceae_UCG-003 was significantly negatively correlated with MCT-1 $(P<0.05)$, and positively correlated with acetic acid $(P<0.05)$.

\section{Discussion}

Tibetan goat is a special ruminant animal in Qinghai-Tibet Plateau, which provide energy for the body through rumen fermentation of natural herbage. The main components of herbage are cellulose and hemicellulose, while cellulase (CL), as an important enzyme for degrading and digesting fiber substances, is mainly secreted and attached to fiber substances by microbiota, so as to be utilized by the body for degrading and digesting [16]. It has been reported that more than $75 \%$ of VFAs produced by fermentation are absorbed by rumen epithelium as the main energy source of ruminants [18]. This study found that the cellulase activity and fermentation product VFAs in the rumen of rams were higher than that of ewes, and the VFAs produced in the rumen need to be transported into the blood circulation through related proteins in the rumen epithelium to provide energy for the body. However, related research reported that monocarboxylate transporter MCT-1 played a crucial role in the transport and absorption of VFAs in rumen epithelial membrane [21]. MCT-1 and MCT-4, as two subtypes with different affinity for VFAs, both play a role in VFAs transport in the gastrointestinal tract of ruminants [21]. In addition, Connor et al. found that there was a synergistic effect between the VFA-/H+ exchange carrier DRA and the MCT-1 [21]. This indicated that VFAs was co-transported by multiple transporters in the rumen epithelium. This study also found that the expression of the VFAs transport genes MCT-1 and DRA increased significantly in the 
ewes. We speculated that the ewes transported more VFAs to provide energy and maintain nutritional needs during the process of adapting to the high altitude environment, resulting in a relatively low concentration of VFAs in the rumen. In addition, the content of $\mathrm{NH}_{3}-\mathrm{N}$ was another important indicator of the rumen fermentation function, reflecting the degradation rate of nitrogenous substances and the utilization of nitrogen in ruminants, and also reflecting rumen fermentation status to a certain extent. In this study, the low ammonia nitrogen content of rams may be related to the rumen fermentation capacity of rams and the rapid degradation rate of nitrogen-containing substances, as well as nutrients such as crude protein in plateau forages.

Tibetan goat can live in the plateau environment and maintain the reproduction of the population, which is related to the host genome and microbiota called "second genome" [4]. Studies have reported that dietary fiber is the main energy source for intestinal bacterial fermentation, which can affect estrogen level and may also shape the gut microbiota [19]. Similarly, the intake of fiber also promotes higher levels of dietary microbiota diversity [40]. This study sequenced the rumen microbiota in Tibetan goat of different sex, and found that there were significant sex differences in the microbiota diversity of Tibetan goat, and the rumen microbiota diversity of ewes was higher than that of rams. Elderman et al. found that the composition of the gut microbial community between male and female mouse was significantly different and the diversity of microbiota was higher in female mouse than that of male mouse, which was consistent with the results of this study [25]. It was generally believed that microbiota with high diversity and richness is beneficial to host health, and high microbiota richness was beneficial to microbiota stability [26]. For ruminants, Firmicutes and Bacteroides played an important role in degrading fiber and digesting complex carbohydrates $[27,28]$. This study found that Bacteroidetes and Firmicutes were the main dominant phyla, which was consistent with the results of Wang et al. [29]. Bacteroides degraded high molecular weight organic matter and improved innate immune response by enhancing intestinal mucosal barrier function [31, 32]. Firmicutes carries many genes encoding enzymes related to energy metabolism, and produced many digestive enzymes to decompose various substances, thereby helping the host digest and absorb nutrients [33], and in this study, the abundance of Firmicutes in ewes is significantly higher than that in rams. In the rumen ecosystem, Spirochaetes played a role in the degradation of cellulose, pectin and phytic acid, the utilization of fermentable carbohydrates and the production of volatile fatty acids [34]. This study found that the relative abundance of Spirochaetes in ewes was significantly higher than that of rams, which was inconsistent with the results of Hu et al. [36]. Related research reported Lachnospira had the ability to produce lactic acid and acetic acid, which can be further metabolized into butyric acid or propionic acid, while low concentration of butyrate acid promoted constipation by inhibiting mucin secretion $[41,42]$. This is consistent with the previous results of VFAs in this study, and it is speculated that the role of Lachnospira may lead to the higher VFAs in rams. At the genus level, Prevotella_ 1 was the dominant genus, Prevotella_ 1 was considered to be related to the production of propionic acid [38]. In this study, the concentration of propionic acid in rumen was higher in rams than in ewes, which corresponded to the abundance of Prevotella_1 in rams. In addition, This study showed that many Cellulolytic bacteria, such as Ruminococcus_1, Fibrobacter and Pyramidobacter were identified. Cellulolytic bacteria were an important type of bacteria that played a key role in degrading 
cellulose materials to produce VFAs in the rumen [39]. Therefore, in this study, the cellulolytic bacteria was significantly higher in ewes than in rams, indicating that ewes had a strong fermentation capacity under the harsh plateau environment. Ewes can decompose and ferment more cellulose to produce energy substances VFAs, and these VFAs are further transported by rumen epithelial transporters into the blood for energy, while in the earlier part of this study the significantly higher expression of VFAs transporter gene in ewes further indicated the capacity of high metabolism. In addition, the measurement results of the density of the rumen microbiota further tested the microbiota diversity. Studies have found that Ruminococcus albus contain cellulosomes that can adhere to and digest cellulose, and its genome encodes cellulase and hemicellulase [35]. Fibrobacter succinogenes is an anaerobic bacterium naturally colonising the rumen and cecum of herbivores, where it deconstructs cellulose into cellobiose and glucose, which serve as carbon sources for growth [37]. In this study, the relative expression of Fibrobacter succinogenes and Ruminococcus albhus were higher in ewes than in rams, which further indicated that ewes had a strong ability to degrade fibrous substances. Privious Studies have reported that the production of propionic acid requires the consumption of rumen hydrogen, which was the main substrate for the growth of methanogens and methanogenesis. The methane produced in the rumen fermentation process is a kind of energy loss to the ruminant host and contributes to the emission of greenhouse gases to the environment [20]. Therefore, we speculated that the significant increase of methanogens in ewes caused energy loss, which in turn leaded to fewer VFAs in the rumen of ewes. The prediction of microbiota gene function found that there were differences in microbiota gene functions in Tibetan goat of different sex. In the KEGG gene family, the functions related to carbohydrate metabolism and energy metabolism were increased in ewes. At the same time, in the COG gene family, replication, recombination and repair, RNA processing and modification were significantly increased in ewes. Studies have reported that DNA damage caused by inflammation, which triggered the activation of DNA repair pathways, and the DNA repair mechanism further protected from DNA damage caused by infection and inflammatory diseases, and participated in innate and adaptive immunity [22]. Therefore, the results of this study showed that in the process of adapting to the high altitude environment, the ewes can develop adaptive immunity to maintain normal healthy activities.

The correlation analysis of rumen microbiota and metabolites VFAs and VFAs transport genes showed that there was a certain correlation among them. Previous reports that Ruminococcaceae_NK4A214_group has a significant and positive correlation with glycolysis [45]. Acetic acid significantly increased the muscle expression of key enzymes involved in fatty acid oxidation and glycolytic-to-oxidative fiber-type transformation in exercise-train mice [44]. Acetyl-CoA generated from acetic acid can be preferentially used in the synthesis of citric acid and then participate in the citric acid biosynthesis [43]. In this study, correlation analysis showed that Ruminococcaceae_NK4A214_group was significantly positively correlated with acetic acid $(P<0.05)$. Therefore, we speculated that Ruminococcaceae_NK4A214_group may have a certain influence on the production of acetic acid by affecting the glycolysis pathway, which further leads to the significant difference in acetic acid between ewes and rams. Ruminococcus_ 1 was significantly negatively correlated with acetic acid $(P<0.05)$, was significantly negatively correlated with MCT-1 $(P<0.05)$, Among them, the MCT-1 transported acetic acid 
and propionic acid into the blood [18]. This result further explained that when the ewe maintained energy requirements, the VFAs transporter can transport relatively more VFAs and then be absorbed and utilized by the rumen epithelium, so that the total concentration of rumen VFAs was significantly lower than that of rams, which further indicated that the ewes had stronger energy metabolism under the traditional grazing condition in plateau.In addition, the anion exchange protein AE2, located in the basal apical membrane of rumen epithelial cells, played an important role in regulating homeostasis [23]. In this study, the expression of $A E 2$ and NHE2 in ewes were significantly higher than those in rams, which may be related to the fact that rumen microbiota in ewes produce more VFAs, so as to prevent rumen acidosis and regulate the homeostasis of rumen. Based on the above results, we found that there was a certain correlation between microbiota-VFAs-host genes (Fig. 7). Under natural grazing conditions in plateaus, rumen microbiota in Tibetan goat of different sex was certain differences, which resulted in different fermentation function among them. Microbiota produced energy substances VFAs by fermenting herbage, which were further transported by rumen epithelial transporters into the blood to supply for energy. This interaction mechanism played an important role in maintaining nutrient balance between tissue cells and rumen environment and regulating rumen environment homeostasis.

\section{Conclusion}

This study revealed the differences of rumen microbiota and rumen fermentation function in Tibetan goat of different sex. VFAs results showed that the acetic acid in rams was significantly higher than that of ewes, and the higher expression of VFAs transporter gene in ewes indicated that ewes had a good efficiency of transporting energy materials. Further 16sRNA sequencing showed that the relative abundance of cellulolytic bacteria in ewes, such as Firmicutes, Fibrobacteres and Spirochaetes, was significantly higher than that in rams, which promoted the degradation and fermentation of herbage.Correlation analysis found that there was a significant positive correlation between acetic acid and Ruminococcaceae_NK4A214_group. Therefore, we speculated that Ruminococcaceae_NK4A214_group may participate in glycolysis and had a certain influence on the production of acetic acid, thus leading to significant differences in acetic acid between ewes and rams. Based on the above results, we found that the differences and interactions among rumen microbiota, VFAs and VFAs transport genes in Tibetan goat of different sex further led to the energy utilization efficiency of ewes and rams, which made ewes have a strong fermentation and metabolism ability in adapting to the special plateau environment.

\section{Abbreviations}

CL: Cellulase; VFAs: volatile fatty acid; $\mathrm{NH}_{3}-\mathrm{N}$ : ammonia nitrogen;

\section{Declarations}

Acknowledgements 
We thank for the funds support: Supporting funds for Innovation Funds of Gansu province institution of higher learning (2020A-52), Youth Mentor of Gansu Agricultural University (GAU-QDFC-2018-11) and National Natural Science Foundation of China (31860688).

\section{Authors' contributions}

Xiu Liu and Yuzhu Luo conceived and designed the experiments, Xinyu Guo, Yuzhu Sha, Weibing Lv and Xiaoning Pu performed all experiments;Xinyu Guo wrote the manuscript with contributions from Xiu Liu and Yuzhu Sha,Jiqing Wang, Jiang Hu and Shaobin Li supervised the project. All authors read and approved the final manuscript.

\section{Funding}

Supporting funds for Innovation Funds of Gansu province institution of higher learning (2020A-52), Youth Mentor of Gansu Agricultural University (GAU-QDFC-2018-11) and National Natural Science Foundation of China (31860688).

\section{Availability of data and materials}

Raw sequence data associated with is being uploaded to NCBI.

\section{Ethics approval and consent to participate}

All studies involving animal were carried out in accordance with the regulations for the Administration of Affairs Concerning Experimental Animal (Ministry of Science and Technology, China; revise in June 2004), and sample collection protocols were approved by the Livestock Care Committee of Gansu Agricultural University (Approval No. GSAU-Eth-AST-2021-24).

\section{Consent for publication}

Not applicable.

\section{Competing interests}

The authors have no conflicts of interest.

\section{Author details}

College of Animal Science and Technology/Gansu Key Laboratory of Herbivorous Animal Biotechnology, Gansu Agricultural University, Lanzhou 730070, China

\section{References}

1. Thompson LG, Yao T, Mosley-Thompson E, Davis ME, Henderson KA, Lin P. A high-resolution millennial record of the south asian monsoon from himalayan ice cores. Science. 2000; 289, 1916- 
1920. doi: $10.1126 /$ science.289.5486.1916.

2. Osadchiy V, Martin CR, Mayer EA. The Gut-Brain Axis and the Microbiome: Mechanisms and Clinical Implications. Clin Gastroenterol Hepatol. 2019; 17, 322-332. doi: 10.1016/j.cgh.2018.10.002.

3. Chaloner A, Greenwood-Van Meerveld B. Sexually dimorphic effects of unpredictable early life adversity on visceral pain behavior in a rodent model. J Pain. 2013; 14, 270-280. doi:

10.1016/j.jpain.2012.11.008.

4. Zhang Z, Xu D, Wang L, Hao J, Wang J, Zhou X, Wang W, Qiu Q, Huang X, Zhou J, Long R, Zhao F, Shi P. Convergent Evolution of Rumen Microbiomes in High-Altitude Mammals. Curr Biol. $2016 \mathrm{Jul}$ 25;26(14):1873-9. doi: 10.1016/j.cub.2016.05.012.

5. Markle JG, Frank DN, Mortin-Toth S, Robertson CE, Feazel LM, Rolle-Kampczyk U, von Bergen M, McCoy KD, Macpherson AJ, Danska JS. Sex differences in the gut microbiome drive hormonedependent regulation of autoimmunity. Science. 2013; 339, 1084-1088. doi: 10.1126/science.1233521.

6. Rizzetto L, Fava F, Tuohy KM, Selmi C. Connecting the immune system, systemic chronic inflammation and the gut microbiome: The role of sex. J Autoimmun. 2018 Aug;92:12-34. doi: 10.1016/j.jaut.2018.05.008.

7. Jin M, Lu J, Fei X, Lu Z, Quan K, Liu Y, Chu M, Di R, Wei C, Wang H. Selection Signatures Analysis Reveals Genes Associated with High-Altitude Adaptation in Tibetan Goats from Nagqu, Tibet. Animals (Basel). 2020; 10, 1599. doi: 10.3390/ani10091599.

8. Deng J, Feng J, Li L, Zhong T, Wang L, Guo J, Ba G, Song T, Zhang H. Polymorphisms, differentiation, and phylogeny of 10 Tibetan goat populations inferred from mitochondrial D-loop sequences. Mitochondrial DNA A DNA Mapp Seq Anal. 2018; 29, 439-445. doi: 10.1080/24701394.2017.

9. Guo J, Tao H, Li P, Li L, Zhong T, Wang L, Ma J, Chen X, Song T, Zhang H. Whole-genome sequencing reveals selection signatures associated with important traits in six goat breeds. Sci Rep. 2018; 8 , 10405. doi: 10.1038/s41598-018-28719-w.

10. Liu C, Wu H, Liu S, Chai S, Meng Q, Zhou Z. Dynamic Alterations in Yak Rumen Bacteria Community and Metabolome Characteristics in Response to Feed Type. Front Microbiol. 2019; 10, 1116. doi: 10.3389/fmicb.2019.01116.

11. Liu X, Sha Y, Dingkao R, Zhang W, Lv W, Wei H, Shi H, Hu J, Wang J, Li S, Hao Z, Luo Y. Interactions Between Rumen Microbes, VFAs, and Host Genes Regulate Nutrient Absorption and Epithelial Barrier Function During Cold Season Nutritional Stress in Tibetan Sheep. Front Microbiol. 2020; 11, 593062. doi: $10.3389 /$ fmicb.2020.593062.

12. Zhong S, Ding Y, Wang Y, Zhou G, Guo H, Chen Y, Yang Y. Temperature and humidity index (THI)induced rumen bacterial community changes in goats. App/ Microbiol Biotechnol. 2019; 103, 31933203. doi: 10.1007/s00253-019-09673-7.

13. Sinha T, Vich Vila A, Garmaeva S, Jankipersadsing SA, Imhann F, Collij V, Bonder MJ, Jiang X, Gurry T, Alm EJ, D'Amato M, Weersma RK, Scherjon S, Wijmenga C, Fu J, Kurilshikov A, Zhernakova A. 
Analysis of 1135 gut metagenomes identifies sex-specific resistome profiles. Gut Microbes. 2019; 10, 358-366. doi: 10.1080/19490976.2018.1528822.

14. Muyzer G, de Waal EC, Uitterlinden AG. Profiling of complex microbial populations by denaturing gradient gel electrophoresis analysis of polymerase chain reaction-amplified genes coding for $16 \mathrm{~S}$ rRNA. Appl Environ Microbiol. 1993 Mar;59(3):695-700. doi: 10.1128/aem.59.3.695-700.1993.

15. Bokulich NA, Subramanian S, Faith JJ, Gevers D, Gordon JI, Knight R, Mills DA, Caporaso JG. Qualityfiltering vastly improves diversity estimates from Illumina amplicon sequencing. Nat Methods. 2013; 10(1):57-9. doi: 10.1038/nmeth.2276.

16. Bhat AH, Khan I, Usmani MA, Umapathi R, Al-Kindy SMZ. Cellulose an ageless renewable green nanomaterial for medical applications: An overview of ionic liquids in extraction, separation and dissolution of cellulose. Int J Biol Macromol. 2019;129:750-777. doi:

10.1016/j.ijbiomac.2018.12.190.

17. Guo H, Zhou G, Tian G, Liu Y, Dong N, Li L, Zhang S, Chai H, Chen Y, Yang Y. Changes in Rumen Microbiota Affect Metabolites, Immune Responses and Antioxidant Enzyme Activities of Sheep under Cold Stimulation. Animals (Basel).2021; 11, 712. doi: 10.3390/ani11030712.

18. Russell JB, Rychlik JL. Factors that alter rumen microbial ecology. Science. 2001; 292(5519):111922. doi: $10.1126 /$ science. 1058830 .

19. Dunphy-Doherty F, O'Mahony SM, Peterson VL, O'Sullivan O, Crispie F, Cotter PD, Wigmore P, King MV, Cryan JF, Fone KCF. Post-weaning social isolation of rats leads to long-term disruption of the gut microbiota-immune-brain axis. Brain Behav Immun. 2018; 68:261-273. doi: 10.1016/j.bbi.2017.10.024.

20. Romero-Huelva M, Ramos-Morales E, Molina-Alcaide E. Nutrient utilization, ruminal fermentation, microbial abundances, and milk yield and composition in dairy goats fed diets including tomato and cucumber waste fruits. J Dairy Sci. 2012; 95(10):6015-26. doi: 10.3168/jds.2012-5573.

21. Connor EE, Li RW, Baldwin RL, Li C. Gene expression in the digestive tissues of ruminants and their relationships with feeding and digestive processes. Animal. 2010; 4(7):993-1007. doi: $10.1017 /$ S1751731109991285.

22. Fontes FL, Pinheiro DM, Oliveira AH, Oliveira RK, Lajus TB, Agnez-Lima LF. Role of DNA repair in host immune response and inflammation. Mutat Res Rev Mutat Res. 2015; 763:246-57. doi: 10.1016/j.mrrev.2014.11.004.

23. Bilk S, Huhn K, Honscha KU, Pfannkuche H, Gäbel G. Bicarbonate exporting transporters in the ovine ruminal epithelium. J Comp Physiol B. 2005; 175(5):365-74. doi: 10.1007/s00360-005-0493-1. Epub 2005 May 31.

24. Helrich K, Helrich K. Official Methods of Analysis of the AOAC.1990.

25. Elderman M, Hugenholtz F, Belzer C, Boekschoten M, van Beek A, de Haan B, Savelkoul H, de Vos P, Faas M. Sex and strain dependent differences in mucosal immunology and microbiota composition in mice. Biol Sex Differ. 2018; 9(1):26. doi: 10.1186/s13293-018-0186-6. 
26. Tap J, Furet JP, Bensaada M, Philippe C, Roth H, Rabot S, Lakhdari O, Lombard V, Henrissat B, Corthier G, Fontaine E, Doré J, Leclerc M. Gut microbiota richness promotes its stability upon increased dietary fibre intake in healthy adults. Environ Microbiol. 2015; 17(12):4954-64. doi: 10.1111/1462-2920.13006.

27. Thoetkiattikul H, Mhuantong W, Laothanachareon T, Tangphatsornruang S, Pattarajinda $\mathrm{V}$, Eurwilaichitr L, Champreda V. Comparative analysis of microbial profiles in cow rumen fed with different dietary fiber by tagged 16S rRNA gene pyrosequencing. Curr Microbiol. 2013; 67(2):130-7. doi: 10.1007/s00284-013-0336-3.

28. Spence C, Wells WG, Smith CJ. Characterization of the primary starch utilization operon in the obligate anaerobe Bacteroides fragilis: Regulation by carbon source and oxygen. J Bacteriol. 2006; 188(13):4663-72. doi: 10.1128/JB.00125-06.

29. Wang X, Zhang Y, Wen Q, Wang Y, Wang Z, Tan Z, Wu K. Sex Differences in Intestinal Microbial Composition and Function of Hainan Special Wild Boar. Animals (Basel). 2020; 10(9):1553. doi: 10.3390/ani10091553.

30. Van Soest PJ, Robertson JB, Lewis BA. Methods for dietary fiber, neutral detergent fiber, and nonstarch polysaccharides in relation to animal nutrition. J Dairy Sci. 1991;74(10):3583-97. doi: 10.3168/jds.S0022-0302(91)78551-2.

31. Thomas F, Hehemann JH, Rebuffet E, Czjzek M, Michel G. Environmental and gut bacteroidetes: the food connection. Front Microbiol. 2011; 2:93. doi: 10.3389/fmicb.2011.00093.

32. Magrone T, Jirillo $E$. The interplay between the gut immune system and microbiota in health and disease: nutraceutical intervention for restoring intestinal homeostasis. Curr Pharm Des. 2013;19(7):1329-42. doi: 10.2174/138161213804805793.

33. Kaakoush NO.Insights into the Role of Erysipelotrichaceae in the Human Host. Front Cell Infect Microbiol. 2015; 5, 84. doi: 10.3389/fcimb.2015.00084.

34. Hess M, Sczyrba A, Egan R, Kim TW, Chokhawala H, Schroth G, Luo S, Clark DS, Chen F, Zhang T, Mackie RI, Pennacchio LA, Tringe SG, Visel A, Woyke T, Wang Z, Rubin EM. Metagenomic discovery of biomass-degrading genes and genomes from cow rumen. Science. 2011; 331, 463-467. doi: 10.1126/science.1200387.

35. Suen G, Stevenson DM, Bruce DC, Chertkov O, Copeland A, Cheng JF, et al.. Complete genome of the cellulolytic ruminal bacterium Ruminococcus albus 7. J Bacteriol. 2011; 193, 5574-5575. doi: 10.1128/JB.05621-11.

36. Hu D, Chao Y, Li Y, Peng X, Wang C, Wang Z, Zhang D, Li K. Effect of Gender Bias on Equine Fecal Microbiota. J Equine Vet Sci. 2021; 97, 103355. doi: 10.1016/j.jevs.2020.103355.

37. Arntzen MØ, Várnai A, Mackie RI, Eijsink VGH, Pope PB. Outer membrane vesicles from Fibrobacter succinogenes $\mathrm{S} 85$ contain an array of carbohydrate-active enzymes with versatile polysaccharidedegrading capacity. Environ Microbiol. 2017; 19, 2701-2714. doi: 10.1111/1462-2920.13770.

38. Strobel HJ. Vitamin B12-dependent propionate production by the ruminal bacterium Prevotella ruminicola 23. Appl Environ Microbiol. 1992; 58, 2331-2333. doi: 10.1128/aem.58.7.2331- 
2333.1992.

39. Pan X, Xue F, Nan X, Tang Z, Wang K, Beckers Y, Jiang L, Xiong B. Illumina Sequencing Approach to Characterize Thiamine Metabolism Related Bacteria and the Impacts of Thiamine Supplementation on Ruminal Microbiota in Dairy Cows Fed High-Grain Diets. Front Microbiol. 2017; 8, 1818. doi: 10.3389/fmicb.2017.01818.

40. Fernandes KA, Kittelmann S, Rogers CW, Gee EK, Bolwell CF, Bermingham EN, Thomas DG. Faecal microbiota of forage-fed horses in New Zealand and the population dynamics of microbial communities following dietary change. PLoS One. 2014; 9,112846. doi: 10.1371/journal.pone.0112846.

41. Jalanka J, Major G, Murray K, Singh G, Nowak A, Kurtz C, Silos-Santiago I, Johnston JM, de Vos WM, Spiller R. The Effect of Psyllium Husk on Intestinal Microbiota in Constipated Patients and Healthy Controls. Int J Mol Sci. 2019; 20, 433. doi: 10.3390/ijms20020433.

42. Canani RB, Costanzo MD, Leone L, Pedata M, Meli R, Calignano A. Potential beneficial effects of butyrate in intestinal and extraintestinal diseases. World J Gastroenterol. 2011;17, 1519-1528. doi: 10.3748/wjg.v17.i12.1519.

43. Des Rosiers C, David F, Garneau M, Brunengraber H. Nonhomogeneous labeling of liver mitochondrial acetyl-CoA. J Biol Chem. 1991;266(3):1574-8.

44. Pan JH, Kim JH, Kim HM, Lee ES, Shin DH, Kim S, Shin M, Kim SH, Lee JH, Kim YJ. Acetic acid enhances endurance capacity of exercise-trained mice by increasing skeletal muscle oxidative properties. Biosci Biotechnol Biochem. 2015;79(9):1535-41. doi: 10.1080/09168451.2015.1034652.

45. Pacífico C, Petri RM, Ricci S, Mickdam E, Wetzels SU, Neubauer V, Zebeli Q. Unveiling the Bovine Epimural Microbiota Composition and Putative Function. Microorganisms. 2021;9(2):342. doi: 10.3390/microorganisms 9020342 .

\section{Figures}




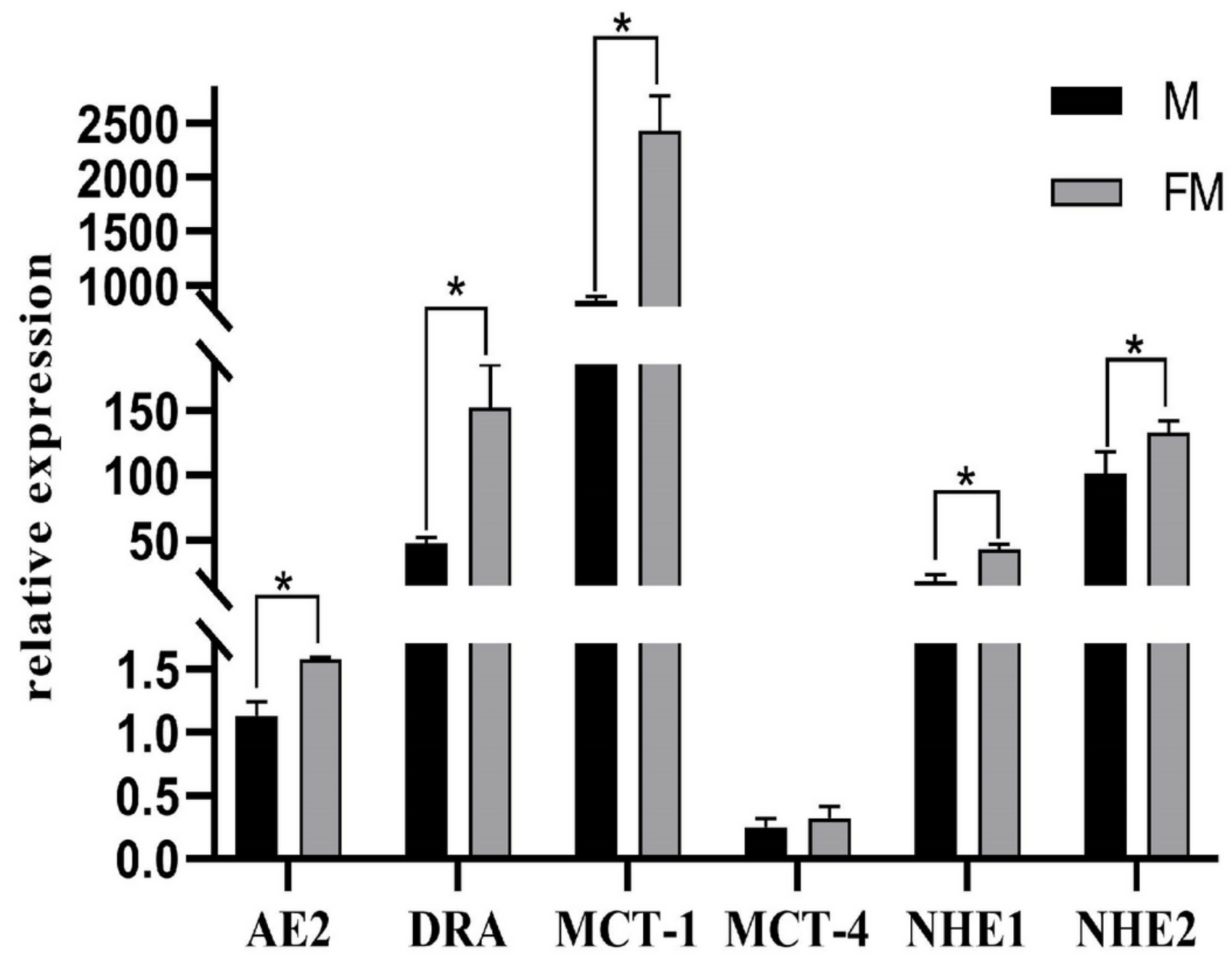

Figure 1

Expression of VFAs transport related gene * indicates that VFAs transport genes are significantly different in different sex 
A

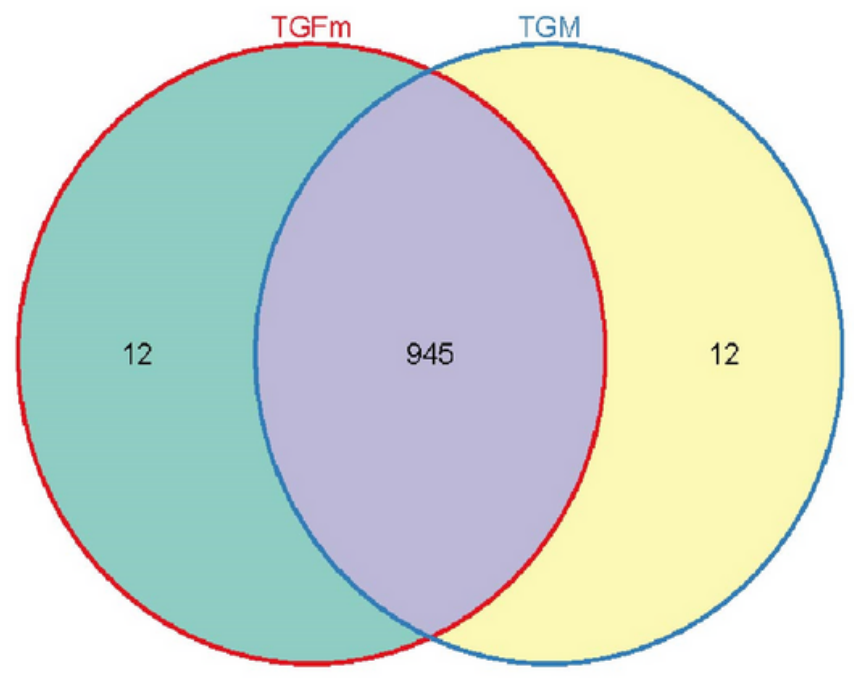

B

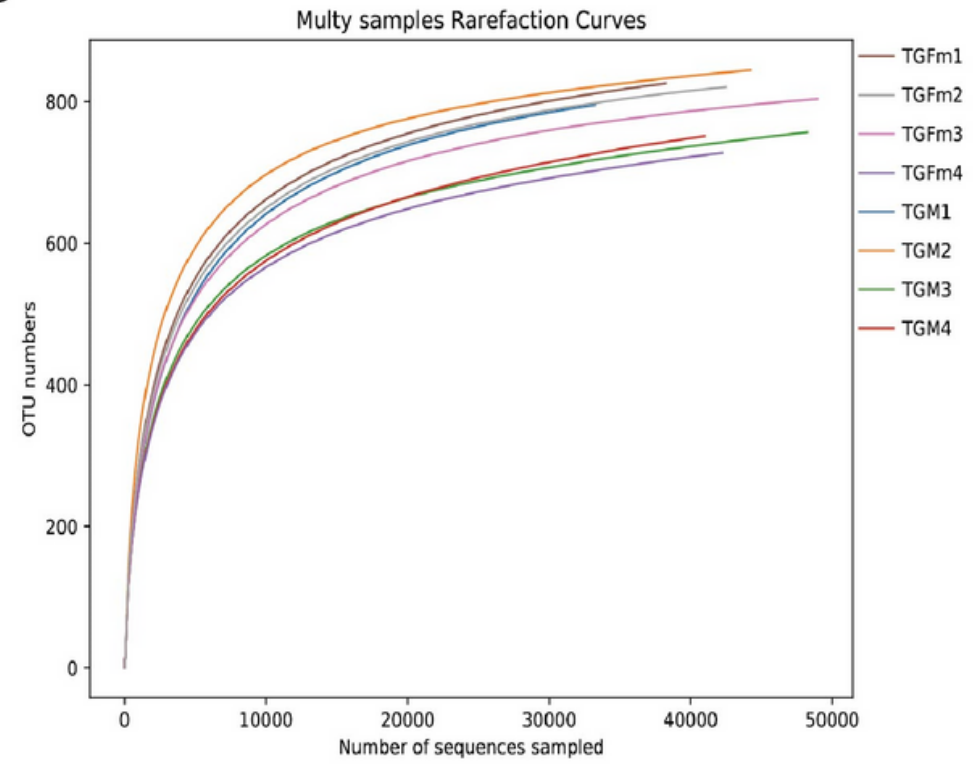

Figure 2

A. OTU-Venn diagram analysis of ewes and rams B. Dilution curve analysis

A

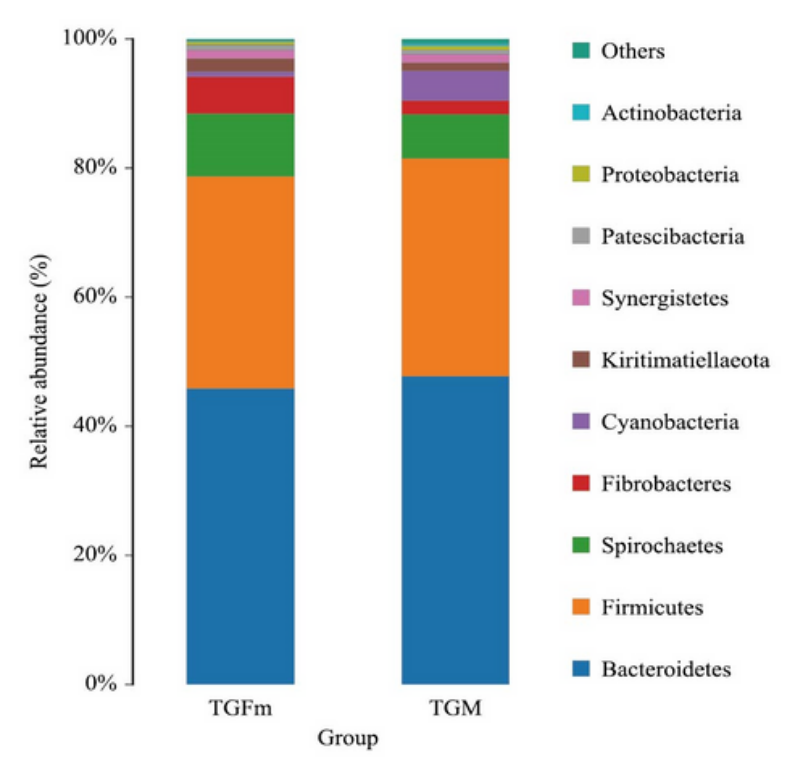

B

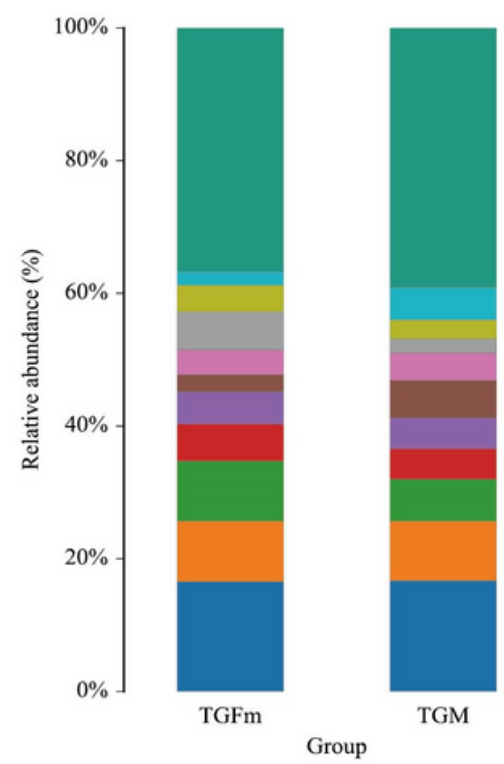

Others

Quinella

Succiniclasticum

Fibrobacter

uncultured_bacterium_f_Lachnospiraceae

n uncultured_bacterium_f_Prevotellaceae

[ Rikenellaceae_RC9_gut_group

n uncultured_bacterium_f_Muribaculaceae

a Treponema 2

nuncultured_bacterium_f_F082

- Prevotella 1

\section{Figure 3}

\section{A. Relative abundance of phylum horizontal species}




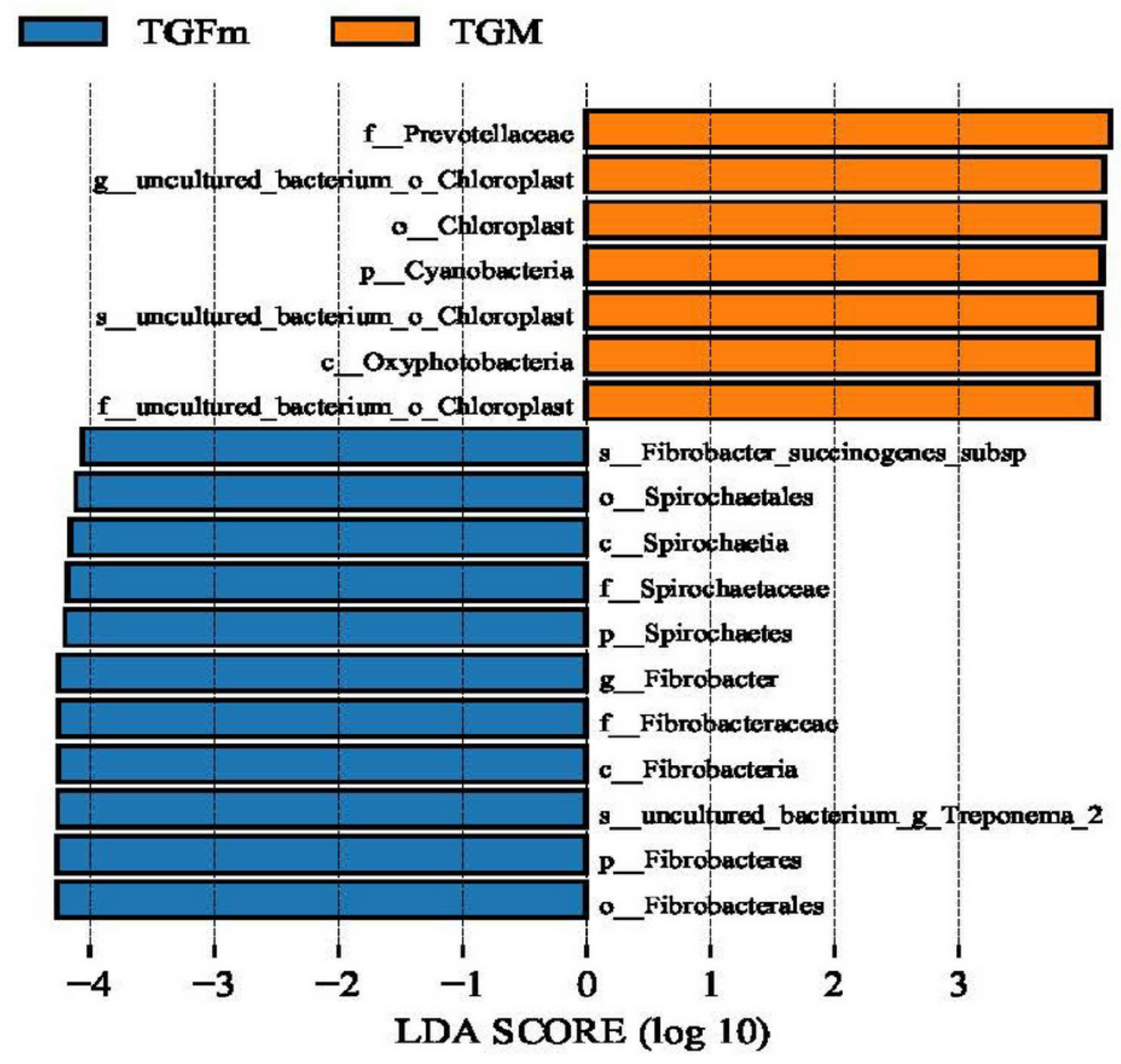

Figure 4

LDA value distribution histogram. LDA value $>4$, and the length of the bar chart represents the influence of different species 


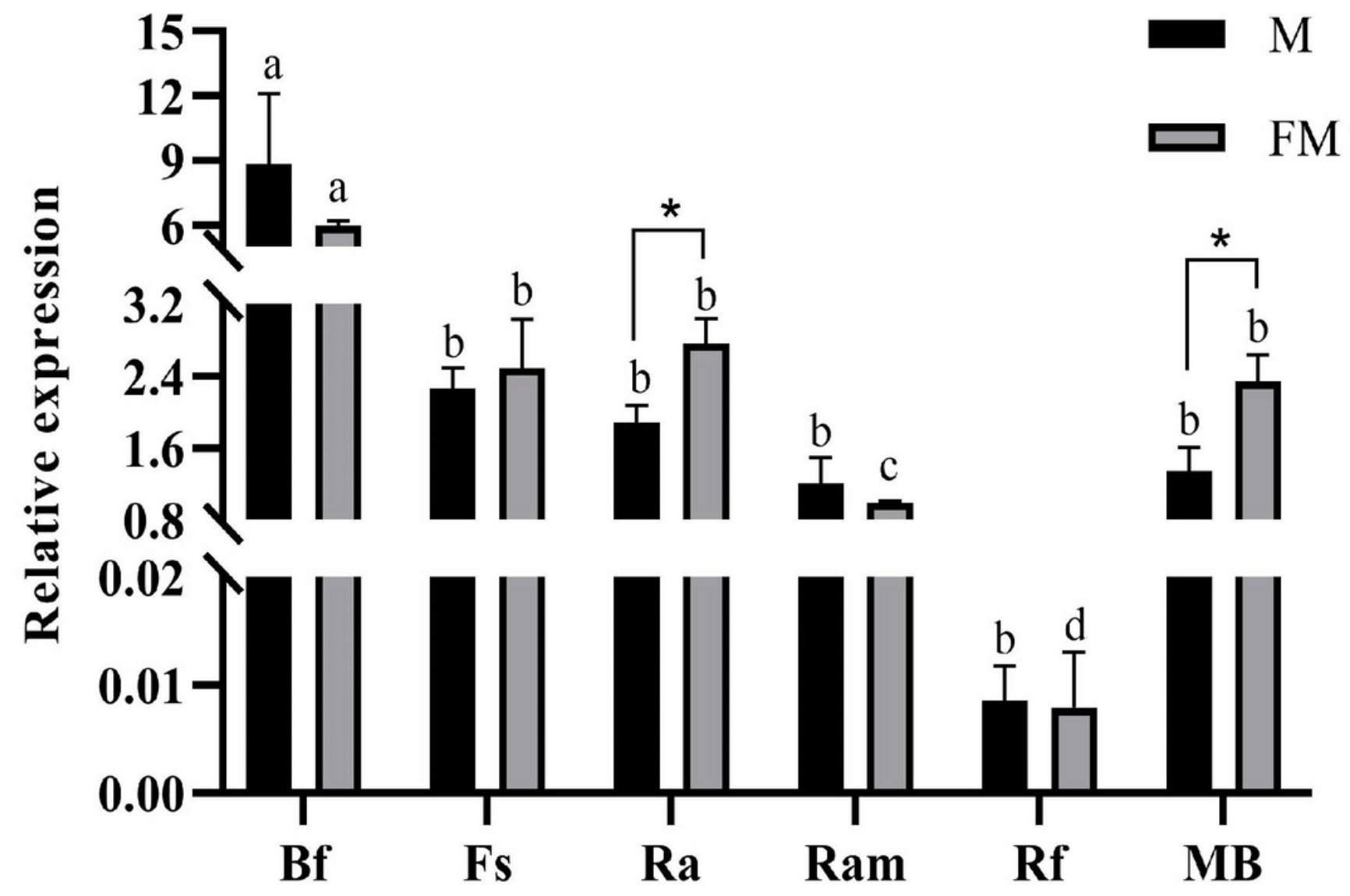

Figure 5

Determination of rumen microbiota density of Tibetan goat of different sex NOTE:For different sexes, the same bacterial species marked with * indicates that there are significant differences between different sexes $(P<0.05)$. In the same sex, different bacterial species marked with different lowercase letters indicate significant differences $(P<0.05)$, and different bacterial species marked with the same lowercase letters indicate that the difference is not significant $(P>0.05)$. 


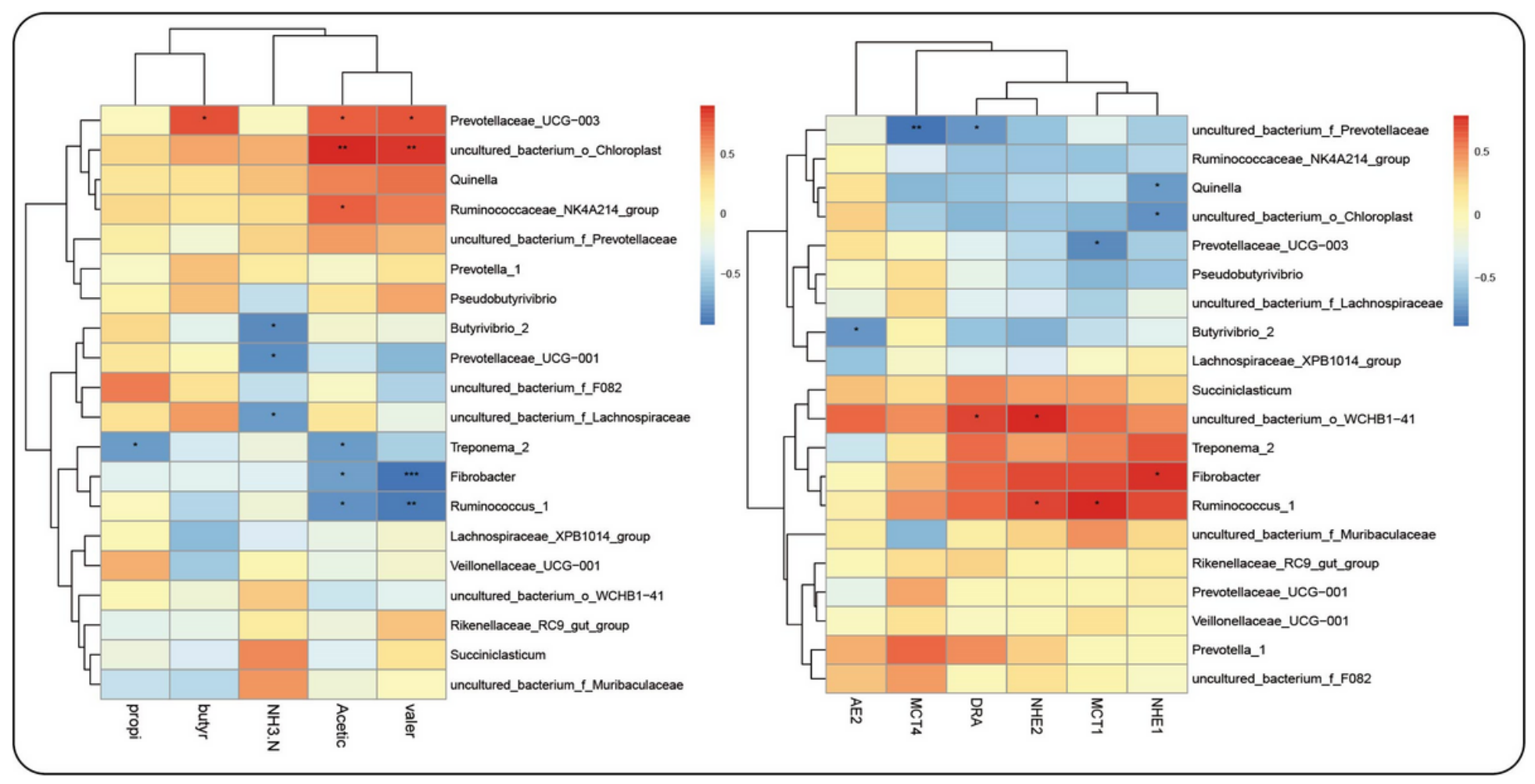

Figure 6

Correlation heat map. $\left({ }^{*} P<0.05, * \star P<0.01, * \star \star P<0.001\right)$ 


\section{Rumen}

\section{Microorganisms}

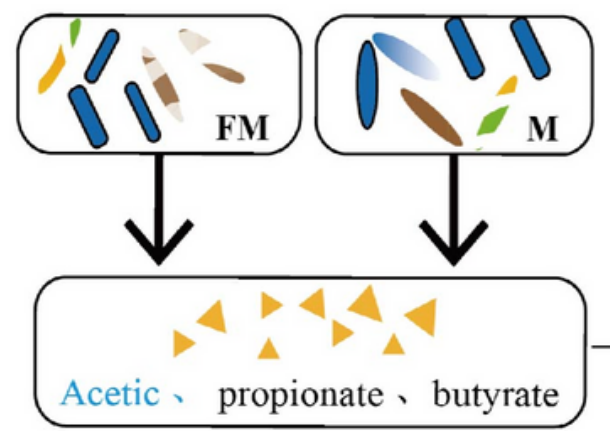

Fibrobacter、

Ruminococcus_1、

Erysipelotrichaceae_UCG-004、

Oscillospira、

Pyramidobacter

Lachnospira、

Ruminococcaceae_NK4A214_group

Volatile fatty acid transporter (MCT-1)

NHE1

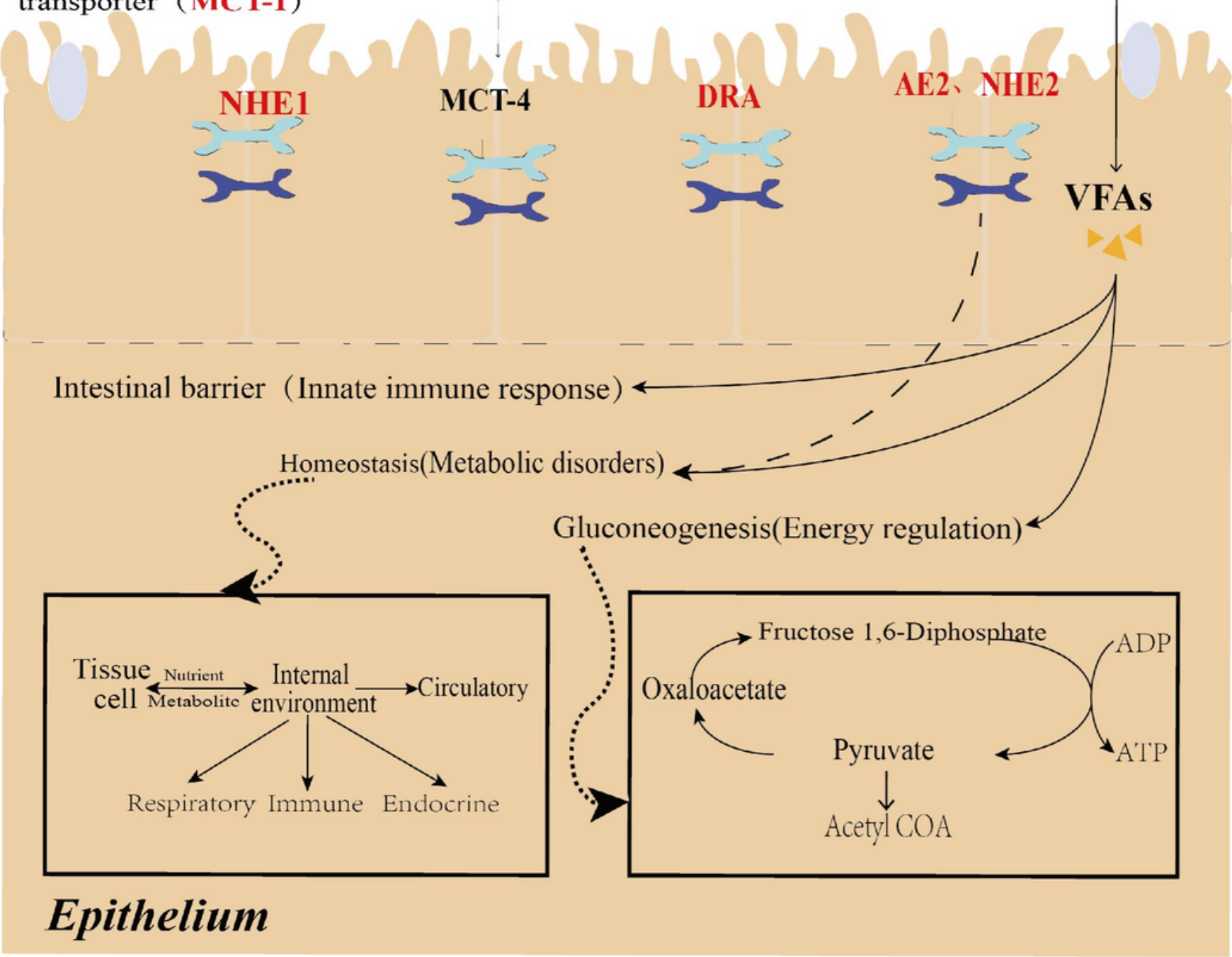

Tight junctions

\section{Figure 7}

The mechanism model of Tibetan goat rumen microbes producing VFAs and regulating the organism.Red letters indicate upregulation in ewes and blue letters indicate upregulation in rams. Black letters indicate that there is no significant difference between males and females. 